\title{
Indicadors de riquesa i de desigualtats en el món artesanal de Barcelona als segles XVI i XVII. Dots i famílies en el gremi de terrissers
}

\author{
IsAAC GARcía-Oses* \\ Universitat de Barcelona
}

\section{Resum}

Aquest treball presenta els dots com a font que permet escatir els nivells de riquesa i de desigualtats econòmiques entre l'artesanat barceloní d'època moderna. Partint de l'anàlisi de gairebé I60 capítols matrimonials (I5OI-I777), amb participació de diferents oficis, realitzem una proposta de categorització dels sectors socioproductius. Analitzem principalment el grup de terrissers, prenent-lo com a exemple per exposar l'evolució de les quantitats dotals i la seva categorització social. A través dels diferents oficis d'aquest sector professional, hom podrà evidenciar les desigualtats internes de riquesa i de poder adquisitiu.

Paraules clau: dot, capítols matrimonials, terrissers, poder adquisitiu, estalvi.

* Aquest treball es va desenvolupar en el marc del contracte per a la Formación de Profesorado Universitario (FPU), finançat pel Ministeri d'Educació, Cultura i Esport; dins el projecte «La articulación del territorio y relaciones mediterráneas en la Cataluña de la época moderna» (HAR2or5-64954-P), finançat pel Ministeri d'Economia i Competitivitat; i dins el Grup de Recerca Consolidat «Grup d'Estudis d'Història del Mediterrani Occidental. Societat, poder i cultura a l'època moderna (GEHMO)» (2017SGR215). 
Indicadores de riqueza y de desigualdades en el mundo artesanal de Barcelona en los siglos XV $y$ XVI. Dotes y familias en los gremios de alfarería

\section{Resumen}

Este trabajo presenta las dotes como la fuente que permite percibir los niveles de riqueza y de desigualdades económicas entre el artesanado barcelonés de época moderna. Partiendo del análisis de casi ciento sesenta capitulaciones matrimoniales (I5OI-I777), con la participación de diferentes oficios, realizamos una propuesta de categorización de los sectores productivos. Analizamos principalmente el grupo de alfareros, tomándolos como ejemplo para exponer la evolución de las cuantías dotales y su categorización social. A través de los diferentes oficios de este grupo productivo se podrán evidenciar las desigualdades internas en lo que se refiere a riqueza y a poder adquisitivo.

Palabras clave: dote, capítulos matrimoniales, alfareros, poder adquisitivo, ahorro.

Wealth and inequality indicators in the craft world of Barcelona in the I6th and I7th centuries. Dowries and families in the pottery guilds

\section{Abstract}

This paper presents dowries as a source for estimiting the levels of wealth and economic inequality among the Barcelona artisans of modern times. To do this, starting from the analysis of almost I6o prenuptial agreements (I5OI1777), with the participation of different trades, a proposal is made for the categorization of unions. The main analysis looks at the potters' guild, taking it as an example to explain the evolution of dowry amounts and their social categorization. Internal inequalities in terms of wealth and purchasing power can be shown through the different crafts of this guild.

Keywords: dowry, prenuptial agreement, pottery, purchasing power, savings. 


\section{Les escletxes del tancament de les elits}

El tancament de les elits gremials ha estat objecte d'estudi per diferents autors, que han analitzat els gremis de velluters valencians o dels sastres madrilenys. Però sempre des de la perspectiva de la normativa interna de les corporacions d'ofici, i dedicant una atenció especial a l'evolució de les taxes d'examen que l'aprenent havia de pagar. 'Però l'entroncament dels treballadors nouvinguts a les estructures gremials d'època moderna va ser irremeiable. En aquest sentit, tot i que les ordinacions semblaven vetllar pel tancament de les elits gremials, la participació d'aquests treballadors en les qüestions més familiars i menys tècniques va contribuir a la regeneració de les famílies i a la pervivència de la productivitat dels espais de treball, encara que fos a les mans d'una família nouvinguda. ${ }^{2}$

Els capítols matrimonials són una font que presenten un avantatge inherent: els dots atorgats es concreten en una quantitat monetària i, per tant, són susceptibles de ser tractats des de la vessant quantitativa. Com ha apuntat Rosa Congost, el sistema hereditari de Catalunya va concedir un paper molt important al dot que aportaven les famílies de les núvies. Entre les raons que enumera s'ha de destacar el fet que els capítols matrimonials, i especialment els dots, permeten observar les diferències econòmiques entre les famílies i els sectors professionals. L'homogeneïtat pel que fa a les quantitats que hi apareixen, segons la

I. Ricardo Franch Benavent, «Los maestros del colegio del arte mayor de la seda de Valencia en una fase de crecimiento manufacturero (I686-I755)", Hispania: revista española de historia, 246 (20I4), p. 49; José N. Nieto SÁNCHEZ, «El acceso al trabajo corporativo en el Madrid del siglo xviII: una propuesta de análisis de las cartas de examen gremial», Investigaciones de Historia Económica-Economic History Research, 9 (2013), p. Ioo; Stephan R. Epstein, «Craft Guilds, Apprenticeship and Technological Change in Preindustrial Europe», The Journal of Economic History, 58 (1998), pp. 648-713.

2. Juan Carlos Zofío Llorente, «Artesanos ante el cambio social. Los curtidores madrileños en el siglo Xviı», Cuadernos de Historia Moderna, 37 (20I2), pp. I32I33; Pier Paolo Viazzo i Katherine A. Lynch, «Anthropology, Family History and the Concept of Strategy», International Review of Social History, 47 (2002), pp. 423-452; Johan Dambruyne, "Guilds, Social Mobility and Status in Sixteenth-Century Ghent», International Review of Social History, 43 (1998), pp. 3I-54. 
historiadora, permet tenir un millor coneixement de les desigualtats socials, millor que no pas el que permet emprar altres fonts notarials, com ara els inventaris post mortem, alterats per la valoració a l'alça o a la baixa dels objectes detallats. ${ }^{3}$

Així, les quantitats dotals ens permetrien, d'una banda, evidenciar les desigualtats socials i econòmiques dins un mateix collectiu i, d'altra banda, aproximar-nos a la realitat socioprofessional d'un sector productiu parant atenció als oficis, tant del nuvi com del pare de la núvia. La part que donava la núvia en general podia contenir una suma pecuniària —el dot estimat — i una part formada per béns mobles —el dot inestimat. Cap norma, però, semblava que regís la quantitat aportada en dot per les núvies i llurs progenitors, sinó que era convinguda segons la disponibilitat i la possibilitat de la casa, un fet que devia marcar les desigualtats tant entre membres d'una mateixa generació familiar com entre membres d'un mateix sector socioprofessional. ${ }^{4}$

Això no obstant, la quantitat dotal que la núvia aportava al matrimoni acostumava a ser la part legítima de l'herència paternal i maternal. Aquesta situació devia implicar que els dots de les núvies sempre se situessin per sobre de la legítima que, d'altra banda, obtenien els fills cabalers, en tant que l'aportació era la base sobre la qual s'establien relacions familiars i econòmiques. Nogensmenys, les inflacions de les quantitats dotals foren una constant durant l'època moderna, i van arribar a la seva màxima expressió a finals del XVII i principis del XVIII. ${ }^{5}$

3. Rosa Congost Colomer, «Els dots com a indicadors de les desigualtats socials i de la seva evolució en el temps", en R. Ros, coord., Els capitols matrimonials: una font per a la Història Social, Associació d'Història Rural de les Comarques Gironines, Girona, 2010, p. I67.

4. Mikes Jani TüNDE, «Legislació històrica de la família catalana medieval i moderna», Butlletí de la Societat Catalana d'Estudis Històrics, 38 (2017), p. I77.

5. Llorenç Ferrer i Alòs, "Capítols matrimonials i història de la família», a R. Ros, coord., Els capitols matrimonials: una font per a la Història Social, Associació d'Història Rural de les Comarques Gironines, Girona, 20Io, p. 137; Rosa Congost I Colomer, Notes de societat: La Selva, I768-1862, Consell Comarcal de La Selva, Santa Coloma de Farners, 1992, p. 39; Isabel Amparo Baixauli Juan, Casar-se a 
Així, el treball que presentem pretén analitzar diferents capitulacions matrimonials per tal de plantejar una proposta que serveixi com a indicadora dels nivells de riquesa de les famílies menestrals barcelonines i, a més, observar desigualtats econòmiques entre les nissagues del mateix sector productiu. Per dur a terme aquesta anàlisi prendrem com a exemple els diferents oficis que formaven les corporacions gremials de terrissers a Barcelona, en tant que no van defugir cap de les consideracions exposades. A més, la producció ceràmica de Barcelona, especialment la de pisa, va ser de les més destacades durant els segles XVI i XVII, va prendre el relleu a la fama de la producció valenciana i va competir amb les produccions italianes i franceses. ${ }^{6}$ No obstant, tot i ser el sector productiu més important de les societats històriques, no podem escatir del tot la rellevància dels gremis terrissers atesa l'escassa producció d'estudis socioeconòmics de què disposem. ${ }^{7}$ Per això, amb aquest treball, ultra les consideracions exposades, pretenem contribuir a l'estudi històric i documental d'aquest sector.

l'antic règim. Dona i família a la València del segle XVII, Publicacions de la Universitat de València, València, 2003, p. 27.

6. Antoni de Capmany, Memorias históricas sobre la marina, comercio y artes de la antigua ciudad de Barcelona, Madrid, I792, I, za part, p. 70; Julia Beltrán DE Heredia Bercero i Núria Miró i Alaix, «El comerç de ceràmica a Barcelona als segles XVI- XVII: Itàlia, França, Portugal, els tallers del Rin i Xina», QUARHIS: Quaderns d'Arqueologia i Història de la Ciutat de Barcelona, 6 (20IO), pp. I4-9I; "El comerç als segles XVI- XVII a través dels materials arqueològics apareguts a Barcelona», Barcelona quaderns d'història, I8 (2012), pp. 333-334.

7. Joan M. Vila i Carabasa, "La participació de l'estament artesanal en el Consell de la ciutat (segles XIII-XVI)», Barcelona quaderns d'història, 4 (200I), pp. I83I92; Maria Carmen RIU DE MARTín, "Vida cotidiana de los ceramistas y vidrieros barceloneses», Anuario de Estudios Medievales, I (2004), pp. 307-355; "Notas sobre la condición socioeconómica de los ceramistas barceloneses del siglo XV», en Atti del IX Congresso Internazionale sulla Ceramica Medievale nel Mediterraneo, Edizioni All'Insegna del Giglio, Firenze, 20I2, pp. 46I-466; Josep Antoni Cerdì i Mellado, «La confraria de Sant Hipòlit dels ollers, gerrers, rajolers i escudellers de Barcelona», Butlletí Informatiu de Ceràmica, 88-9I (2006), pp. 32-55. 


\section{El dot mitjà entre els matrimonis dels terrissers}

Així doncs, per estudiar el nivell de riquesa familiar hem considerat prendre com a mostra un conjunt de capítols matrimonials en què els contraents o els seus progenitors pertanyien al sector de la terrissa, i d'aquesta manera elaborar una proposta que permeti una aproximació a la classificació econòmica de la població artesanal barcelonina.

L'estudi s'ha dut a terme amb un total de 158 capítols matrimonials datats entre I5OI i I777. Ara bé, només en I40 capitulacions s'ha obtingut informació relativa a la situació socioprofessional del pare de la núvia, una qüestió que ha permès observar d'una banda quin era l’origen de la família i de l'altra la capacitat d'estalvi per tal de poder fer front al dot. En analitzar les dades globals, sense distingir entre períodes cronològics més petits o concrets, la mitjana aritmètica inicial dels dots queda fixada en 197 lliures. Per tal de poder extreure una més bona informació de les dades, hem suprimit els oficis dels quals només teníem un únic exemple, considerant que no serien representatives en aquest cas i que ens podrien distorsionar els resultats a l'hora de fer-ne el tractament estadístic. La mostra final, així, ha quedat reduïda a un total de II6 casos corresponents a vint-i-dues activitats professionals.

El nostre objectiu és fer una primera proposta de categorització social, de manera que hem optat per estudiar les quantitats dotals de manera conjunta, sense diferenciar franges cronològiques, la qual cosa podria arribar a constatar uns resultats més acurats per a cada període preestablert. Al final d'aquest treball hom podrà observar, però, que les quanties dotals van experimentar fluctuacions al llarg del període considerat, si el deflactem amb productes de la vida quotidiana. Per això podem considerar que aquesta font és un indicador de la riquesa i de les desigualtats econòmiques.

La informació quantitativa que ens han aportat el dots ens han permès dur a terme una anàlisi estadística que evidencia la distribució de les quantitats dotals. La representació gràfica s'ha fet mitjançant un boxplot o diagrama de caixa, en tant que ens permet observar on es concentra el $50 \%$ de la mostra a través de l'amplitud interquartílica (IqR) (Fig. I). El cos de la gràfica, format per dues caixes entre les 70 i 
les 200 lliures, ens permet observar de manera preliminar dos comportaments diferents.

La situació de la mediana a les I2o lliures, dibuixa, a més, una distribució de les quantitats dotals molt més concentrada per sota d'aquest valor que no pas per sobre. L'asimetria lleugerament positiva, és a dir, en què la mediana és inferior al valor de la mitjana dels dots, ens indica que les quantitats aportades durant el període estudiat manté una concentració per sota de les I74 lliures. L'asimetria, a més, ens permet asseverar que els dots de la caixa inferior, amb uns valors entre les 70 i les I2o lliures, serien els més habituals entre les famílies terrisseres. Per la seva banda, els de valors superiors, més dispersos, dibuixen una cua amb dades superiors a la mediana.

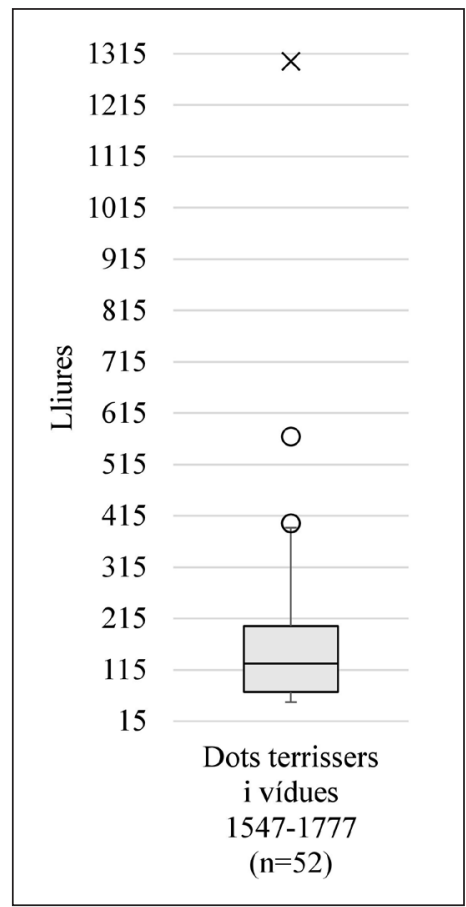

Figura I. Distribució de les quantitats dotals del sector de la terrissa de Barcelona mitjançant un boxplot, I547-I777. S'hi han marcat amb un cercle $(\mathrm{O})$ els valors atípics, i amb una creu $(x)$ els extrems. 
El diagrama de caixa també ens permet constatar que entre els ceramistes barcelonins hi devia haver una certa voluntat d'aconseguir dotar les filles amb una xifra al voltant de les Ioo lliures, una quantitat gairebé mínima per poder casar-les en condicions òptimes. Precisament el centenar de lliures va constituir el dot d'Antiga, filla de l'oller Pere Palet, el març de i647. ${ }^{\circ}$ També va ser de la mateixa quantitat l'aportació dotal que va efectuar la família d'escudellers Balle a la seva filla Mariàngela l'any i657 per tal que pogués contraure matrimoni amb Josep Fortuny, un jove fuster del poble de Constantí. En aquest cas, però, el dot no estava format per una quantitat única, sinó que va ser el resultat de la suma de 25 lliures aportades pel pare Agustí Balle i les restants 75 per diferents causes pies per maridar donzelles: 25 lliures de la causa pia de la confraria dels escudellers «com a filla de mestre», unes altres 25 de la dels blanquers, en tant que entre els seus avantpassats comptava amb artesans d'aquest ofici, i les darreres 25 llegades en testament per Maria, vídua de Francesc de Fora, pagès. ${ }^{9}$

Durant el Set-cents, aquesta xifra també va significar un objectiu a aconseguir per tal que la família no caigués en la pobresa més absoluta. Jerònima, filla de Jeroni Duxer, un escudeller difunt, després de recórrer a diverses causes pies, va poder aportar, juntament amb les dues caixes nupcials «segons ús y costum de Barcelona», ${ }^{\text {io }}$ el centenar de lliures: 25 procedents de la causa pia del capità Lluc d'Olivella, I6 de la del taverner Guillem Bruna i les restants 58 lliures i io sous de la legíti-

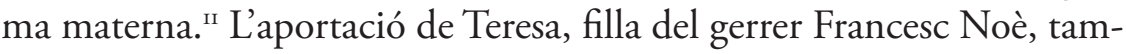
bé es va establir en aquesta quantitat, però amb la característica important que fou aportada íntegrament en efectiu, juntament amb les prescrites caixes nupcials i s'hi afegí, a més, tot allò que calia per realitzar una fornada, tant en llenya com en vernís i altres materials. ${ }^{12}$

8. Arxiu Històric de Protocols de Barcelona (AHPB), not. Josep Galcem, 665/3I, núm. II2, I647, març, 3.

9. AHPB, not. Ramon Vilana Perles, 763/88, ff. I-4V, I657, gener, 6.

Io. AHPB, not. Ramon Congost, 80I/10, I675, agost, I8.

II. AHPB, not. Francesc Rossinés, 858/16, ff. I60-I65v, I702, gener, II.

I2. AHPB, not. Pere Pau Pujol, 910/28, ff. 263-266v, I72I, febrer, I6. 
Més enllà de les limitacions superiors, s'han pogut calcular alguns valors atípics, numèricament més distants a la resta de dades. Seguint el test proposat per John W. Tukey i de David R. Brillinger, ${ }^{13}$ hem considerat valor atípic lleu el que es pot localitzar I, 5 vegades per sota del primer quartil $Q_{1}$ o per sobre del tercer $Q_{3}$. De la mateixa manera, hem considerat valor extrem aquell la representació del qual excedia 3 vegades per sota del $Q_{1}$ i per sobre del $Q_{3}$.

Els resultats, que han estat uns valors atípics lleus, superaven àmpliament les 400 lliures. Aquesta quantitat va ser la que es va comprometre a pagar Mariàngela, filla de l'escudeller Antoni Porcià, l'any I627. L'aportació incloïa la legítima paterna i alguns llegats familiars, juntament amb una petita contribució de 25 lliures de la causa pia dels escudellers. ${ }^{\mathrm{I}}$ Més de mig segle més tard, les 400 lliures tornen a ser el gruix total del dot aportat per Anna Maria, filla del difunt gerrer Jaume Puigdoure, format per l'herència paterna, pel llegat d'un familiar i per 25 lliures promeses pel notari Josep Güell uns anys abans. ${ }^{\text {I5 }}$ També considerem atípiques les 569 lliures de Beatriu, filla de l'escudeller Guillem de Pau, establert l'any I600. ${ }^{16}$ Quant als valors extrems, només s'ha detectat un cas, el corresponent al dot de I.30o lliures aportat per Maria, filla de Pau Feliu, escudeller. Es va tractar d'un dot lliurat majoritàriament en quantitats en efectiu, a més d'algunes robes, mobles i joies. ${ }^{17}$

I3. John W. Tukey, Exploratory Data Analysis, Addison-Wesley, Reading, I977; David R. Brillinger, "Data Analysis, Exploratory», a B. Badie, D. Berg-Schlosser i L. Morlino, eds., International Encylopedia of Political Science, SAGE Publications, Thousand Oaks, 20II, II, p. 533.

I4. AHPB, not. Pere Llunell, 586/86, I627, gener, 31.

I5. AHPB, not. Josep Güell, 8II/96, ff. 233-238, I703, novembre, 3.

16. AHPB, not. Galceran Francesc Devesa, 510/38, I600, abril, I.

17. AHPB, not. Josep Güell, 8II/94, ff. 366-372, I686, novembre, 2. 


\section{Evolució de la capacitat econòmica}

Però, com ja hem esmentat a l'inici, els valors dotals per ells mateixos no són útils per evidenciar la força econòmica d'una família ni la seva possible capacitat d'estalvi, en tant que estaven subjectes a les fluctuacions pròpies de cada període històric. Per tant, hem de fer una aproximació a la capacitat d'estalvi i a l'esforç econòmic que els calia a les famílies de les núvies si volien arribar al dot típic.

I per considerar aquest esforç hem de deflactar les quantitats dotals. En aquest sentit, es va posicionar Rosa Congost, considerant molt encertadament que per comparar els dots de determinades àrees geogràfiques o períodes era necessari transformar aquell valor en un de real de la unitat monetària emprada. Només podríem prendre en consideració les quantitats dotals sempre que es comptés amb un altre indicador que permetés fer la comparació. ${ }^{18}$

Són diversos els valors que es poden escollir per deflactar els dots, com ara el preu de productes manufacturats, el de les jornades de treball o el dels aliments. L'inconvenient que presenten radica en el fet que no comptem amb una sèrie continuada per calcular la deflactació o per poder reconstruir-la, ni que sigui parcialment. En el cas del preu dels productes manufacturats, per exemple, tot i els esforços de Gaspar Feliu per reconstruir diferents sèries del segles XVI al XVIII, les dades amb què es compten són relativament escasses i presenten diversos buits. ${ }^{19}$ Quant a les jornades de treball, caldrien encara més variables per reconstruir una sèrie temporal, com ara quin ofici faríem servir com a índex i, fins i tot, dins la seva estructura, quin valor prendríem com a punt de referència: el jornal d'un mestre, el d'un oficial o el d'un manobre. En la documentació, per la seva banda, no sempre resulta evident a quina categoria socioprofessional correspon el salari esmentat, i les fonts tampoc ajuden a considerar el jornal com a retri-

I8. Congost Colomer, "Els dots com a indicadors", p. I74.

19. Gaspar Feliu i Montrort, Precios y salarios en la Cataluña moderna. Combustibles, productos manufacturados y salarios, Banco de Espańa, Madrid, I99I, p. 39. 
bució de tot un dia de feina, amb l'alimentació o amb el possible allotjament inclosos. ${ }^{20}$

Tot i que d'aliments n'hi havia de diferents categories i qualitats, l'ésser humà n'ha considerat sempre alguns de primordials per a la seva alimentació i d'altres de secundaris. No és estrany que la necessitat d'adquirir-los ens permeti resseguir el rastre documental de la seva compravenda, facilitant una possible reconstrucció del nivell de vida. Entre els aliments, caldria diferenciar entre els que eren de consum diari d'aquells als quals només es recorria en comptades ocasions, com era el cas de la carn, considerat el tercer graó alimentari, just per sota del peix salat. ${ }^{2 \mathrm{E}} \mathrm{El}$ preu de les quarteres de blat, que no del seus derivats com ara el pa, que podia ser elaborat amb altres cereals, el podem considerar com a valor que ens ajudi a deflactar els dots.

La deflactació en base els preus de la quartera de blat ja ha estat realitzada de manera orientativa per Rosa Congost, analitzant l'evolució dels dots de la família Heras d'Adri durant el segle XviII en el món rural. ${ }^{22}$ Per dur a terme aquesta operació, va tenir en compte la mitjana del preu de la quartera de blat durant deu anys, constituïts per l'any d'assignació del dot i els nou anys precedents. En el nostre cas, per a la ciutat de Barcelona, hem realitzat la reconstrucció de l'evolució del preu del blat prenent com a referència les dades aportades per Gaspar Feliu, a partir dels treballs d'Emili Giralt, d'Eva Serra i de Pierre Vilar. ${ }^{23}$

20. Ibidem, p. 69.

2I. Gaspar Feliu i Montrort, Precios y salarios en la Cataluña moderna. Alimentos, Banco de España, Madrid, I99I, pp. 7I, I2O.

22. Miquel Heras de Puig, Biografia ó explicació del arbre geneologich de la descendència de casa Heras de Adri, I350-I850, Associació d'Història Rural de les Comarques Gironines, Girona, 200I.

23. Feliu i Montfort, Precios y salarios en la Cataluña moderna. Alimentos, pp. 4I-44; Emili Giralt i Raventós, «En torno al precio del trigo en Barcelona durante el siglo XVI", Hispania: revista espanyola de historia, 60 (1958), pp. 3I-68; Eva SERra I Puig, Pagesos i senyors a la Catalunya del segle XVII: baronia de Sentmenat I590-I729, Crítica, Barcelona, I988; Pierre VILAR, Catalunya dins l'Espanya moderna: recerques sobre els fonaments econòmics de les estructures nacionals, Edicions 62, Barcelona, I964I968, II, pp. 377, 440, III, p. 378. 
Al llarg d'aquestes tres centúries es poden evidenciar diferents períodes històrics de la ciutat de Barcelona. El segle Xvi va transcórrer en un lleuger ascens constant. L'estabilitat econòmica de l'inici del Cinccents només estava marcada per un lleuger augment en el preu de les quarteres durant la dècada de 1530 i posteriorment amb un ascens més constant durant els darrers vint anys de la centúria. Tot i els símptomes de crisi durant els primers anys del XVII, el preu de la quartera de blat es va mantenir en un altiplà que només es va veure afectat per la Guerra de Secessió (I640-I652). El conflicte marcà el preu nominal del blat, el va fer arribar a les cotes més altes poc abans de I652 i després es va anar estabilitzant progressivament. De manera irregular però constant, la tendència a l'alça a partir de la dècada de I690 només es va veure truncada pel sotrac en tots els àmbits que va significar la Guerra de Successió (I7OI-I7I4). El panorama posterior va tornar a fer disminuir el preu del blat fins a la dècada de I740. Les darreries del Set-cents es van caracteritzar per l'increment del preu del blat de manera exagerada.

Per realitzar el procés de deflactació s'han pres els valors dels dots de 40 capítols matrimonials en què la núvia era de família terrissera $i$, a més, aquesta vegada s'hi han afegit els dots de les núvies que, tot i no ser filles, hem pogut identificar com a vídues de terrissers. D'aquesta manera, s'ha aconseguit un total de 52 valors dotals. Per evitar que hi haguessin diversos valors per a cada any, s'ha realitzat la mitjana de tots ells, i la mostra ha quedat reduïda a 45 dots distribuïts de la manera que mostra la taula $\mathrm{I}$.

La deflactació dels dots mostra una marcada pèrdua de poder adquisitiu al llarg del període estudiat (taula I). Les quantitats dotals transformades a valors reals mostren una progressiva reducció del poder adquisitiu per part de les famílies. La difícil situació que travessaren queda molt clarament evidenciada entre la dècada de 1550 i la de I580. La inflació dotal no es documenta, ara bé, fins al primer terç del segle Xvir. Durant aquell centúria, apunta Maria Adela Fargas per a l'oligarquia barcelonina, la inflació estava vinculada a una progressiva alça en la competència amb l'oferta per sobre de la demanda. Una situació agreujada per a les famílies, que van haver de recórrer a altres solucions, com ara el celibat "voluntari» tant de fills com de filles i, fins 
Taula I. Relació de les quantitats dels dots en lliures de Barcelona, la seva deflactació en quarteres de blat d'aquell any i en índex 1547-I777.

\begin{tabular}{|c|c|c|c|c|}
\hline Any & $\begin{array}{c}\text { Dots } \\
\text { (ll.) }\end{array}$ & $\begin{array}{c}\text { Preu (ll.) } \\
\text { quartera de blat }\end{array}$ & $\begin{array}{c}\text { Dots } \\
\text { deflactats }\end{array}$ & $\begin{array}{c}\text { Índex= } \\
\text { I547-I777 }\end{array}$ \\
\hline $\mathrm{I} 547$ & 70 & $\mathrm{I}, 2 \mathrm{I}$ & 58,09 & $4 \mathrm{I}, 38$ \\
\hline $\mathrm{I} 556$ & $5 \mathrm{O}$ & $\mathrm{I}, 55$ & $32,3 \mathrm{I}$ & 29,56 \\
\hline $\mathrm{I} 558$ & $\mathrm{IOI}$ & $\mathrm{I}, 35$ & 74,59 & 59,52 \\
\hline $\mathrm{I} 559$ & $8 \mathrm{O}$ & $\mathrm{I}, \mathrm{I} 9$ & $67,6 \mathrm{O}$ & 47,45 \\
\hline $\mathrm{I} 567$ & 200 & $2, \mathrm{OI}$ & 99,73 & $\mathrm{II} 8,22$ \\
\hline $\mathrm{I} 570$ & $\mathrm{I} 42$ & $\mathrm{I}, 46$ & 97,26 & 83,94 \\
\hline $\mathrm{I} 578$ & 200 & $2,4 \mathrm{I}$ & 82,90 & $\mathrm{II} 8,22$ \\
\hline $\mathrm{I} 589$ & 50 & $2, \mathrm{I} 5$ & 23,28 & 29,56 \\
\hline $\mathrm{I} 590$ & 60 & $2, \mathrm{I} 4$ & 28,07 & 35,47 \\
\hline $\mathrm{I} 592$ & $\mathrm{I} 56$ & $2,6 \mathrm{I}$ & $59,7 \mathrm{I}$ & $92,2 \mathrm{I}$ \\
\hline $\mathrm{I} 593$ & $\mathrm{I} 20$ & 2,45 & 48,93 & 70,93 \\
\hline $\mathrm{I} 595$ & $7 \mathrm{I}$ & $2, \mathrm{I} 3$ & 33,37 & $4 \mathrm{I}, 97$ \\
\hline $\mathrm{I} 598$ & 25 & 2,40 & $\mathrm{IO}, 4 \mathrm{I}$ & $\mathrm{I} 4,78$ \\
\hline $\mathrm{I} 599$ & 200 & 2,40 & $83,5 \mathrm{I}$ & $\mathrm{II} 8,22$ \\
\hline $\mathrm{I} 600$ & 569 & 2,60 & $2 \mathrm{I} 8,85$ & 336,34 \\
\hline $\mathrm{I} 604$ & $\mathrm{I} 50$ & $\mathrm{I}, 8 \mathrm{I}$ & 82,76 & 88,67 \\
\hline $\mathrm{I} 605$ & 200 & 2,47 & $8 \mathrm{I}, 09$ & $\mathrm{II} 8,22$ \\
\hline $\mathrm{I} 608$ & 20 & 2,55 & 7,84 & $\mathrm{II}, 82$ \\
\hline $\mathrm{I} 609$ & 200 & 2,20 & $90,9 \mathrm{I}$ & $\mathrm{II} 8,22$ \\
\hline $\mathrm{I} 6 \mathrm{I} 3$ & 75 & 2,22 & 33,78 & 44,33 \\
\hline $\mathrm{I} 6 \mathrm{I} 5$ & $\mathrm{I} 37$ & 2,07 & 66,28 & $8 \mathrm{I}, \mathrm{I} 2$ \\
\hline $\mathrm{I} 6 \mathrm{I} 6$ & 60 & $\mathrm{I}, 89$ & $3 \mathrm{I}, 79$ & 35,47 \\
\hline $\mathrm{I} 6 \mathrm{I} 8$ & 50 & $2, \mathrm{I} 8$ & 22,99 & 29,56 \\
\hline $\mathrm{I} 627$ & $\mathrm{I} 50$ & 2,26 & 66,30 & 88,67 \\
\hline $\mathrm{I} 635$ & $\mathrm{I} 20$ & 2,50 & 48,00 & 70,93 \\
\hline $\mathrm{I} 636$ & $\mathrm{I} 20$ & 2,26 & 53,04 & 70,93 \\
\hline $\mathrm{I} 638$ & $\mathrm{I} 56$ & $2,2 \mathrm{I}$ & 70,74 & 92,33 \\
\hline $\mathrm{I} 640$ & 60 & 2,35 & 25,49 & 35,47 \\
\hline $\mathrm{I} 64 \mathrm{I}$ & 75 & 2,23 & 44,33 \\
\hline
\end{tabular}

(Continua a la página següent)

Pedralbes, 4I (202I), I43-I64, ISSN: O2II-9587, DOI: IO.344/PEDRALBES2O2I.4I.4 


\begin{tabular}{|c|c|c|c|c|}
\hline Any & $\begin{array}{l}\text { Dots } \\
\text { (ll.) }\end{array}$ & $\begin{array}{c}\text { Preu (ll.) } \\
\text { quartera de blat }\end{array}$ & $\begin{array}{c}\text { Dots } \\
\text { deflactats }\end{array}$ & $\begin{array}{c}\text { Índex= } \\
\text { I547-I777 }\end{array}$ \\
\hline I642 & IO8 & 2,38 & 45,47 & 63,84 \\
\hline I647 & IOO & 4,03 & 24,84 & $59, \mathrm{II}$ \\
\hline I648 & 200 & 5,05 & 39,60 & II 8,22 \\
\hline 1650 & 75 & 7,00 & IO,7I & 44,33 \\
\hline I657 & IOO & 3,08 & 32,48 & $59, \mathrm{II}$ \\
\hline 1675 & 256 & 2,40 & 106,85 & 151,59 \\
\hline 1678 & I35 & 5,20 & 25,96 & 79,80 \\
\hline $\mathrm{I} 686$ & I.300 & 2,68 & 485,98 & 768,44 \\
\hline I688 & 140 & 2,55 & 54,82 & 82,76 \\
\hline 1695 & I6I & $2,9 \mathrm{I}$ & 55,48 & 95,38 \\
\hline I697 & 200 & 3,25 & 61,54 & II 8,22 \\
\hline I7O2 & IOO & 3,08 & 32,52 & $59, \mathrm{II}$ \\
\hline 1703 & 300 & 3,43 & 87,59 & 177,33 \\
\hline I72I & IOO & 3,33 & 30,00 & $59, \mathrm{II}$ \\
\hline $\mathrm{I} 728$ & 300 & $3, \mathrm{I} 3$ & 95,75 & 177,33 \\
\hline I777 & 370 & $6, \mathrm{II}$ & 60,46 & 218,46 \\
\hline
\end{tabular}

i tot, l'augment del nombre de membres de la família que ingressaven en la carrera eclesiàstica per evitar una major despesa en dots a la unitat familiar. ${ }^{24}$

No obstant, durant el primer terç del segle XviI sembla que les quantitats arriben a una relació prou estable amb el preu de la quartera de blat, ja sigui per un nombre major de dades o per una interpretació adient de la progressiva davallada del valor real dels dots. A la taula I hom pot observar que durant els anys del Cinc-cents es va mantenir en favor del preu de la quartera de blat, tal com dèiem. La inflació de fi-

24. María Adela Fargas Peñarrocha, Les dones en l'Antic Règim, Editorial de la Universitat Oberta de Catalunya, Barcelona, 2003, p. 73; Fargas Peñarrocha, La genealogía cautiva: propiedad, movilidad y familia en Barcelona, I500-I650, Publicacions de la Universitat de València, València, 20I2, cap. 2. 
nals de la centúria va acabar per ensorrar els dots dels terrissers. El panorama general que s'albirava era prou advers perquè les famílies poguessin dotar les filles amb unes quantitats que coincidissin amb el nivell de vida que marcava el preu del blat. La manca d'informació durant el període de més augment del preu del cereal a les dècades centrals del Sis-cents només permet observar una petita vall entre I647 i I657, en coincidència amb el conflicte de secessió que va assotar el Principat. Tot i que a partir de les dècades posteriors la situació es tornà a estabilitzar, la pèrdua de poder adquisitiu de les famílies terrisseres va ser més que evident als darrers moments del XVII i a principis del XVIII.

Una situació econòmica greu i complicada que hem pogut resseguir més enllà de l'estricte marc familiar. La documentació notarial, però també la produïda per les mateixes corporacions artesanals, ens han permès confirmar que un dels pitjors moments que van experimentar els terrissers va coincidir entre els anys 1620 i I680. Van ser diverses les ocasions a les quals tant la corporació d'ollers, gerrers i rajolers com la d'escudellers van haver de recórrer a les autoritats per buscar noves formes de finançament —amb l'augment de les taxes de mestria, per exemple - ${ }^{25}$ o a la creació de diversos censals per valor de més de 6.800 lliures. ${ }^{26}$

\section{Una proposta de classificació dotal en intervals}

El dot normal, doncs, entre els terrissers de Barcelona i durant el període estudiat, devia estar situat al voltant del centenar de lliures. Sembla que aconseguir arribar a aquesta xifra garantia considerar-se un grup social amb una capacitat adquisitiva suficient per a dotar les filles amb

25. Arxiu Històric de la Ciutat de Barcelona (AHCB), Consell de Cent, Registre d'ordinacions, IV-27, ff. 43v-44, I623, juny, I6; IV-I84, f. 262, I675, agost, 2I.

26. AHPB. not. Jacint Sescases, 798/37, f. 82-87, I69I, abril, 2; AHPB. not. Josep Güell, 8II/I08, f. 49-57, I69I, abril, 2. El deute calculat a finals del segle XVII pujava a un total de I.500 lliures encara per pagar als diferents creditors de la corporació d'escudellers. 
dignitat. Per aquest motiu, a nivell metodològic, creiem que és oportuna una reflexió. Una de les qüestions que s'han de tenir presents a l'hora d'establir les franges o intervals consisteix a prendre la decisió de com iniciar i finalitzar els intervals de cada tram. Som conscients que en funció d'on es decideixi establir la xifra rodona, els resultats mostren unes conclusions o unes altres. És per això que hem considerat que la xifra rodona, l'acabada en o, seria l'inici de cadascuna de les franges o intervals. En aquest sentit, tot i que els valors no resulten idèntics entre el diagrama i la proposta d'intervals, la constatació d'una distribució dels dots similar a la proposta que realitzem ha estat prou significativa. Més encara, la relació entre els intervals proposats i cadascun dels quartils del diagrama de caixa és molt propera, tenint en compte les limitacions de la mostra.

La decisió està fomentada en dues raons: d'una banda, d'aquesta manera s'afavoreix l'estudi dels estaments socials més humils, considerant que la xifra rodona els faria saltar de categoria; de l'altra, com ha afirmat Rosa Congost, és l'opció que ens permet entendre millor l'esforç que una família hauria fet per tal d'assolir la xifra arrodonida del dot de la núvia, és a dir, prendre consciència de la seva capacitat d'estalvi. ${ }^{27}$

Taula 2. Proposta dels sis intervals per classificar els dots de la ciutat de Barcelona en època moderna.

\begin{tabular}{|c|l|l|}
\hline Interval & \multicolumn{1}{|c|}{ Franges } & \multicolumn{1}{c|}{ Proposta de tipologia social } \\
\hline I & fins a 99 & pobres, artesans I \\
\hline II & I00-249 & artesans II \\
\hline III & $250-499$ & artesans III \\
\hline IV & $500-$ I.999 & professions liberals, mercaders \\
\hline V & $2.000-4.999$ & ciutadans honrats, petita noblesa \\
\hline VI & més de 5.000 & aristocràcia \\
\hline
\end{tabular}

27. Congost Colomer, «Els dots com a indicadors», p. 173. 
Com es pot observar a la taula 2, les franges que es proposen fan referència a sis graons que, basant-nos en els apunts de Pere Gifre i de Rosa Congost per a la regió de Girona durant els segles XVI i XVIII respectivament, devien representar els poders adquisitius de la societat barcelonina entre el Cinc-cents i el Sis-cens. ${ }^{28}$ El primer se suposa format pels dots inferiors a 99 lliures i, així, correspon a les famílies més pobres, les quals havien de recórrer majoritàriament a les causes pies per maridar les noies de famílies sense recursos; ${ }^{29}$ a més, incloem en aquesta primera franja les quantitats dels oficis urbans més pobres, com ara els ollers, els traginers o els rajolers. ${ }^{30}$ El segon i el tercer llindar estan delimitats en conjunt per les Ioo i les 500 lliures, amb una franja formada per oficis que podien dotar fins a les 249 , i que devien correspondre a pagesos urbans i a oficis com ara vidriers, ferrers, paraires o escudellers, ${ }^{3 \mathrm{I}}$ i un altre interval per a dots iguals o superiors a les

28. Pere Gifre i Ribas, «El procés final d'implantació dels capítols matrimonials (final de segle XVI-començament de segle XVII)», a R. Ros, coord., Els capitols matrimonials: una font per a la Història Social, Associació d'Història Rural de les Comarques Gironines, Girona, 2010, pp. 65-66.

29. AHPB, not. Ramon Vilana Perles, 763/88, ff. I-4V, I657, gener, 6. En el capítol matrimonial de Mariàngela Balle amb Josep Fortuny, la família d'ella es veu obligada a crear una quantitat dotal digna sumant les diferents aportacions de causes pies.

30. AHPB, not. Francesc Pastor, 65I/64, I642, juliol, 20. Es tracta d'unes capitulacions matrimonials entre ollers, és a dir, Francesc Cassanyes, el nuvi, era fadrí oller i la núvia, Magdalena del Abat, era filla d'un mestre. El dot amb prou feines va arribar a les 66 lliures, amb donacions paternes i algunes causes pies; AHPB, not. Ramon Jaume Huguet, 647/22, I637, setembre, 8. La núvia, Paula Ballera, aporta en dot a l'escudeller Pau Soler les 50 lliures que formen la legítima paterna; AHPB, not. Antic Servat, 58I/9I, I608, juliol, I9. El nuvi, Nicolau Rovira, no pertany al sector productiu de la terrissa, però la núvia, Júlia Ros, és filla d'un rajoler de Calella que no pot aportar en dot més que 20 lliures, que li ha donat el mercader Llorenç Salavert, en tant que criada seva.

3I. AHPB, not. Antoni Joan Fita, 595/89, I62I, juliol, 31. L'escudeller Salvador Serra rep el dot de Joana Vaells, pagès, estipulat en 200 lliures i que conformen l'herència de la núvia; $\mathrm{AHPB}$, not. Josep Galcem, 665/31, núm. 79, I639, desembre, I9. La núvia, Isabel Morera, filla d'un vidrier de Mataró, aporta Ioo lliures en dot, a més de béns mobles per valor d'unes escasses io lliures, al jove escudeller Joan Olivert; 
250 lliures, en què els oficis especialitzats en productes destinats a l'exportació i a la construcció són els més representats. ${ }^{32}$ La quarta franja devia estar formada per l'estament de les professions liberals i dels dedicats al sector comercial. ${ }^{33} \mathrm{~A}$ partir d'aquest interval, les quantitats eren les pròpies de l'oligarquia urbana més que no pas dels sectors productius, i devien superar les 2.000 lliures en el cas dels ciutadans honrats a la cinquena i les 5.000 en el cas de l'aristocràcia a la sisena franja.

Com a proposta per classificar socioprofessionalment els dots, hi ha desviacions i matisos que s'haurien de tenir presents a l'hora de considerar períodes cronològics més curts. No obstant, considerem que és una necessitat imperiosa establir una categorització com la que es presenta per tal de poder analitzar els dots com a indicadors de riquesa, especialment quan no s'ha estudiat prèviament en el sector artesanal. ${ }^{34}$

APHB, not. Francesc Pedralbes, 426/159, doc. 108, I578, desembre, 6. La vídua d'un escudeller, Joana Esbert, filla d'un ferrer, aporta en dot a l'argenter Miquel Vidal un total de 200 lliures; AHPB, not. Antoni Puigvert, 628/5, I627, gener, I4. Es tracta d'una unió entre paraires en què la núvia, Agnès Codina, aporta a Domingo Genís un total de I8I lliures, principalment amb un llegat patern, però complementat per algunes causes pies; AHPB, not. Bernat Puigvert, 536/66, ff. 312-315v, I6I5, agost, 28. En les capitulacions matrimonials, Elisabet Serra, filla de l'escudeller Pere Serra, aporta en dot 200 lliures al seu marit, el flassader Joan Bernat.

32. AHPB, not. Antoni Joan Fita, 595/93, 1630, juny, 9. Maria Ferrer, filla del mestre de cases Pere Ferrer, aporta en dot les 500 lliures llegades per l'herència paterna i altres llegats, a més d'unes terres a Collblanc, al gerrer Francesc Morató.

33. AHPB, not. Francesc Reverter, 703/47, ff. 48-5IV, 1654, gener, 25. Francesca Porcià, filla del mercader Josep Porcià, aporta en dot I.6oo lliures llegades pel seu pare en quatres anualitats, a l'«infanson» Francesc de Aguas; AHPB, not. Francesc Pastor, 65I/64, I647, desembre, 8. El notari Francesc Casanoves concedeix a la seva filla Elisabet Joana un total de 700 lliures per aportar-les com a dot en les capitulacions amb el practicant de notari Josep Garriga.

34. Els dots i els seus valors emprats per indicar la capacitat adquisitiva per a sectors de l'oligarquiaurbana, però no per als sectors artesanals, que per contra constituïen bona part del gruix de la població barcelonina. María Adela Fargas Peñarrocha, Família i poder a Catalunya,I5I6-I626. Les estratègies de consolidació de la classe dirigent, Fundació Noguera, Barcelona, 1997. 
Aplicant els intervals proposats a les quantitats dotals aconseguides (taula 3) es pot observar que, majoritàriament, i com era previsible, les quantitats corresponen al sector artesanal, a l'interval II, amb una representació del 69,29 \% sobre el total. Aquesta classificació, a més, permet observar que gaire bé un Io \% no hauria pogut aconseguir les cent lliures que permetien passar de la pobresa a les classes mitjanes baixes.

Taula 3. Proposta dels sis intervals per classificar els dots de la ciutat de Barcelona en base a II6 dots, I5OI-I777.

\begin{tabular}{|l|l|c|c|l|}
\hline Interval & \multicolumn{1}{|c|}{ Franges } & Casos & \multicolumn{1}{c|}{$\%$} & \multicolumn{1}{|c|}{ Proposta de tipologia social } \\
\hline I & fins a 99 & I3 & 9,29 & pobres, artesans I \\
\hline II & I00-249 & 97 & 69,29 & artesans II \\
\hline III & $250-499$ & 4 & 2,86 & artesans III \\
\hline IV & $500-$ I.999 & 2 & I,43 & professions liberals, mercaders \\
\hline V & $2.000-4.999$ & - & - & ciutadans honrats, petita noblesa \\
\hline VI & més de 5.000 & - & - & aristocràcia \\
\hline Total & & $I I 6$ & $I 00,00$ & \\
\hline
\end{tabular}

Podríem fer la mateixa operació aplicant aquesta vegada la distribució al total de casos en què el pare de la núvia donzella o el marit de la vídua formava part del sector productiu de la ceràmica. El total de capítols matrimonials el conformen 52 documents distribuïts de la manera següent: 2I dels escudellers, 9 dels gerrers, 7 dels ollers, 3 casos dels rajolers i fins a I2 capítols de vídues de terrissers. A la taula 4 podem observar que la meitat dels dots de famílies terrisseres estaven ubicats al segon interval, coincidint amb el grup socioprofessional que hem denominat «artesans II». Novament, el centenar de lliures apareix com a punt d'inflexió per decidir si els terrissers haurien de ser considerats un grup socioprofessional amb recursos escassos i si arribar a la xifra gairebé màgica de les ioo lliures seria l'esperó que tota família mantindria. 
Taula 4. Classificació dels dots aportats per núvies de famílies del ram de la ceràmica, $1556-1728$.

\begin{tabular}{|l|l|c|c|l|}
\hline Interval & \multicolumn{1}{|c|}{ Franges } & Casos & \multicolumn{1}{c|}{$\%$} & \multicolumn{1}{|c|}{ Proposta de tipologia social } \\
\hline I & fins a 99 & I6 & 30,77 & pobres, artesans I \\
\hline II & I00-249 & 29 & 55,77 & artesans II \\
\hline III & $250-499$ & 5 & 9,62 & artesans III \\
\hline IV & $500-$ I.999 & 2 & 3,85 & professions liberals, mercaders \\
\hline V & $2.000-4.999$ & - & - & ciutadans honrats, petita noblesa \\
\hline VI & més de 5.000 & - & - & aristocràcia \\
\hline Total & & 52 & I00,00 & \\
\hline
\end{tabular}

Com argumentàvem més amunt, en decidir establir la xifra rodona a l'inici de cada interval en comptes de situar-lo a la part superior es pot detectar com d'important podia ser l'esforç econòmic d'una família per arribar al llindar. Si novament prenem com a exemple els terrissers, formar part d'una categoria social o d'una altra, precisament, dependria de considerar la xifra rodona com a límit superior de la franja i no a la inversa. En aquest sentit, el nombre de famílies pertanyents a l'interval I passaria de ser del 30,77 \% a un 40,38 \%, mentre que les famílies de l'interval II es reduirien del 55,77 \% al 46,15\%. Una diferència de deu punts percentuals que ens va donant una idea de com d'important arribava a ser la xifra rodona en la mentalitat de la població artesana per disposar d'uns mínims de consideració entre les altres famílies i poder, per tant, arribar a fer un matrimoni que garantís la millora social i econòmica de la generació següent. Haver iniciat cadascuna d'elles amb una xifra rodona, per tant, ha ocasionat que fins a cinc famílies les poguéssim passar a considerar del graó socioeconòmic superior. És a dir, el fet de considerar la xifra arrodonida precisament com a llindar superior i no com a punt de partida ens permet estar en disposició de percebre fins a quin punt era important l'esforç econòmic de la família de la núvia d'estrats socials més humils i, a més, quina era la voluntat de concertar matrimoni amb membres d'un estrat superior per intentar sortir del graó social a què pertanyien. 


\section{Conclusions}

L'entroncament de nous individus a les famílies tradicionals del sector de la terrissa barcelonina va permetre protegir el patrimoni familiar. Les estratègies familiars i matrimonials van fer possible aquesta regeneració del sector davant una progressiva absència de descendència masculina entre els terrissers. Per tant, a més de garantir la projecció social dels seus membres i d'aconseguir millores econòmiques per a la vídua $\mathrm{i}$ la descendència, les polítiques matrimonials que es van dur a terme van estar enfocades a assegurar la continuïtat de l'ofici i a vetllar per la supervivència familiar. Però, més enllà de les consideracions relatives a la confecció de xarxes a nivell horitzontal, creiem que s'ha de fer èmfasi en la capacitat adquisitiva de les famílies del sector de la ceràmica i observar així de quina situació econòmica partien a l'hora d'abordar la construcció de vincles familiars.

L'anàlisi dels capítols matrimonials datats majoritàriament entre els segles XVI i XVII, però no només, ha permès plantejar una primera proposta de categorització de l'estament artesanal segons la quantitat dotal aportada per la família de la núvia. Tot i les limitacions de la mostra, el present treball considera que, entre les famílies artesanes barcelonines, la concentració dotal es produïa entre les I50 i les 200 lliures. Les sis franges permeten categoritzar i classificar els oficis, però també la capacitat econòmica familiar.

La conclusió que podríem extreure tant del tractament estadístic i il.lustrat a través del diagrama de caixa com de la proposta d'intervals, la considerem lligada al fet de valorar l'objectiu de la xifra rodona com un indicador de la fita familiar. El cos del gràfic, format per dues caixes, equival a l'interval I i a l'interval II, amb uns valors per sota de les Ioo lliures en la caixa inferior i per sobre del centenar en la caixa superior. Una fita que permetria analitzar millor quina era la mentalitat de les famílies terrisseres i la seva capacitat estalviadora.

Pel que fa en concret a aquestes famílies, els dots demostren la diferència econòmica i les desigualtats dins del mateix sector productiu. Per una banda, els ollers i els rajolers estaven entre els graons més baixos, mentre que els gerrers i els escudellers van poder arribar a inter- 
vals intermedis. Una distribució a la qual s'haurien d'afegir altres variants, com ara la proliferació de produccions locals destinades al consum diari, la descentralització de la producció rajolera o la rellevància de la producció de gerres per al transport i de pisa per a l'exportació.

En definitiva, les Ioo lliures van significar el llindar mental a superar per garantir, a les núvies en particular i a llurs famílies per extensió, el manteniment del nivell socioeconòmic i també l'assegurança d'una possible projecció social per a les generacions posteriors. En altres paraules, amb la classificació proposada i l'anàlisi efectuada, podem percebre l'esforç econòmic que la família de la núvia d'estrats socials més humils havia de fer, especialment si pretenia concertar matrimoni amb membres d'un interval superior i així sortir del graó social en què s'emmarcaven. 